\title{
Diagnostic Significance of Fine Needle Biopsy and Cell Block in Skin and Subcutaneous Nodules
}

\author{
Raafat Awad Hegazy*1, Abdelmonem Awad Hegazy,3, Hassan Ashour ${ }^{4}$, Ahmed Raafat Hegazy ${ }^{5}$, \\ Esraa Mohammad Nawwar ${ }^{6}$ and Salwan Abdelmonem Hegazy ${ }^{7}$ \\ ${ }^{1}$ Pathology Department, Faculty of Medicine, Zagazig University, Egypt \\ ${ }^{2}$ Anatomy and Embryology Department, Faculty of Medicine Zagazig University, Egypt \\ ${ }^{3}$ Medical Biotechnology Department, College of Biotechnology, Misr University for Science and Technology, Six of October City, Egypt \\ ${ }^{4}$ General Surgery Department, Faculty of Medicine, Zagazig University, Egypt \\ ${ }^{5}$ Pediatric Department, Faculty of Medicine, Zagazig University, Egypt \\ ${ }^{6}$ Dermatology Department, Al-Ahrar Teaching Hospital and Zagazig University Hospitals, Egypt \\ ${ }^{7}$ Dermatology Department, Zagazig University Hospitals, Egypt \\ *Corresponding author: Raafat Awad Hegazy, Pathology Department, Faculty of Medicine, Zagazig University, Egypt
}

\section{ARTICLE INFO}

Received: 慧 October 04, 2021

Published: October 19, 2021

Citation: Raafat Awad Hegazy, Abdelmonem Awad Hegazy, Hassan Ashour, Ahmed Raafat Hegazy, Esraa Mohammad Nawwar, et al., Diagnostic Significance of Fine Needle Biopsy and Cell Block in Skin and Subcutaneous Nodules. Biomed J Sci \& Tech Res 39(3)-2021. BJSTR. MS.ID.006301.

Keywords: FNAC Smear; Cell Block Accuracy; Local Skin Swelling; Nodules; Histopathology; Cytology

\begin{abstract}
Background: Evaluation of patients with cutaneous or subcutaneous nodules, especially if they are multiple, is a diagnostic challenge. This study aimed to investigate smears and cell blocks and compare them with examination of tissue biopsies.

Methods: Fine needle aspiration cytology (FNAC) and cell blocks were done for 225 cutaneous and subcutaneous nodules. Furthermore, histopathological examination was conducted using biopsies.

Results: According to tissue biopsy, benign lesions constituted the most common finding in $180(80 \%)$ cases. The detected cases were lipoma in $35(15.5 \%)$ cases, adipose tissues in $30(13.3 \%)$ cases, 20 fibro lipomas (8.8\%), 20 fibromas (8.8\%), 5 juvenile fibroma (2.2\%), neurofibroma in 5 cases $(2.2 \%)$, sebaceous cyst in 25 cases (11.1\%), implantation cyst, or dermoid cyst 20 cases (8.8\%), pilomatrixoma 5 cases (2.2\%), seborrheic keratosis10 cases (4.4\%) and Madura foot (actinomycosis) in 5 cases $(2.2 \%)$. Intermediate lesions of atypical lipoma were found in 20 cases $(8.8 \%)$. Malignant lesions were 25 cases $(11.11 \%)$ as follows: 10 cases $(4.4 \%)$ basal cell carcinoma, 10 cases $(4.4 \%)$ squamous cell carcinoma and 5 cases $(2.2 \%)$ basosquamous cell carcinoma. For FNAC smear examination, the sensitivity test was $83.01 \%$ and the specificity was $16.66 \%$. For cell blocks examination, the sensitivity and specificity tests were $97.77 \%$, and $100 \%$, respectively.
\end{abstract}

Conclusion: Smear cytology is an easy and quick test for diagnosing skin nodules. Performance of cell blocks improves sensitivity and specificity of smear outcome, but both should be attempted, because the smear may be ineffective in some cases while a cell block cannot be performed in others.

\section{Introduction}

Skin and subcutaneous lesions are a common reason for patients to visit family doctors. Ultrasound is increasingly being used to confirm the diagnosis, but deep lesions must be evaluated

with magnetic resonance imaging (MRI) or computed tomography (CT) to exclude invasion of the underlying structures and/or malignancy [1]. People can experience a wide range of growths and 
skin changes over the course of their lives. Family physicians must be able to distinguish between different skin tumors specially to rule out malignancy [2]. Skin malignancy represents one of the most dangerous types of cancers. It spreads gradually in its early stages, so it is necessary to detect it as soon as possible. It is suggested that skin cancer results from the presence of unpaired strands of deoxyribonucleic acid (DNA) in skin cells, resulting in skin genetic defects or mutations [3]. Evaluation of patients with skin or subcutaneous nodules, especially if they are multiple, is a major problem for clinicians. But with full investigations, the problem becomes easier. However, the definitive diagnosis depends on the pathological reports of tissue biopsy [4]. Easy access to skin nodules provides a good platform for performing fine needle cytology and sampling by pathologists or clinicians. Smear cytology gives several default settings [5]. Depth is more important than width. The skin nodule may be mobile or fixed in the underlying tissue. Proper management of skin or subcutaneous nodules needs to know their exact nature, benign or malignant. These nodules can be accessed through needle aspiration, to make smears and cell blocks; this action is relatively non-invasive outpatient procedure and does not require an operating room or anesthesia. It is also a cheap and fast process. Furthermore, it has been suggested that FNAC breast exam is very useful, relatively quick, inexpensive and less invasive test due to the size of the fine needle, and is easier and safer in some lesions, such as very small lesions or those directly under the skin [6]. The question was how is his sensitivity and specificity, and to what extent can he be relied upon in making a treatment decision? Therefore, this study aimed to verify the reliability of examination of smears and cell masses in the diagnosis of skin and subcutaneous nodules and to compare them with examination of tissue biopsies.

\section{Material and Methods}

\section{Study Design and Samples' Preparation}

Samples of cutaneous or subcutaneous nodules from two hundred and twenty-five patients who decided and gave written consent to participate in the study were selected for this study. These patients were referred from various related clinics in University Hospitals to the Department of Pathology between January 2018 and December 2020. The patients underwent full history taking, general examination for pulse, temperature, respiration rate, body weight, and height. All malignant nodules were primary lesions. The nodules under study were examined clinically for location, size, plurality, shape, consistency, color, if hair was present or not, and whether there was change in color, size, shape, mobility or fixation. Then, a sterile $10 \mathrm{cc}$ plastic syringe was opened, approximately $1 \mathrm{cc}$ of air was taken, the cover was placed on the needle and it was ready for use. The lesion and the surrounding skin underwent a gentle massage with cotton gauze filled with 95\% ethanol, then the needle was inserted close to the periphery of the node (avoiding the center where there may be necrotic material that hinders proper smear taking). The needle was moved in multiple directions with suction; then it was gently removed. Then, the suction site was under pressure with clean, sterile cotton gauze for at least 10 minutes to stop possible bleeding. The needle was gently removed from the syringe, and then 1 drop of the syringe's content was placed on approximately 4 clean glass slides. The smear was prepared by gently moving the blunt end of the syringe.

The remainder of the fluid underwent addition of a mixture of 10\% neutral buffered formalin, and absolute ethanol, 1:1 solution by gentle suction of the previously prepared formalin/ ethanol mixture by the syringe. The smear was allowed to dry on the glass slides, then the slides are placed vertically in the staining container, with the addition of $95 \%$ ethanol, and left for 20 minutes to fix. Fixed smear slides were gently placed in water for $1 \mathrm{~min}$, then in filtered hematoxylin for $5 \mathrm{~min}$, then in tap water for $30 \mathrm{~min}$, then in eosin for $1 \mathrm{~min}$ in tap water for $20 \mathrm{~min}$. The slide smear then, underwent placing in ascending grades of ethanol till absolute alcohol. A cap was placed on the smear, which was then examined with an Olympus XL 30 binuclear microscope. The pellets of cells in the used syringe, were left for one day for fixation, then underwent processing to form paraffin blocks, according to Hegazy Method of tissue processing [7]. Unstained slides were prepared from the paraffin blocks then staining with Hematoxylin \& eosin (H\&E), Giemsa stain and Papaneacolou stain (PAP). Then, the slides were examined with an Olympus XL30 binuclear microscope and photographed with the digital camera on the microscope. Patients in this study underwent FNAC smears, performing cell masses if possible. Then, histological examinations of tissue biopsies were performed after surgical removal of the lesions.

\section{Statistical Analysis}

The correlation between results of FNAC smear and that of cell block study was examined by chi-square test and student T-test. Sensitivity test, \& Specificity test for both FNAC smear and cell blocks were examined in relation to the tissue biopsy, considering the results of tissue biopsy examination as the reference positive cases [8]. All statistical tests were done with considering the significance value of chi-square test and T-test ( $P$ value significance $=0.05$ or less) using SPSS 16.0 for Windows (SPSS Inc. Chicago, Illinois, USA)

\section{Results}

There was a wide range of ages in the patients who underwent this study. Their ages ranged between 2 and 76 years but most of them (80\%) were between $40-45$ years old. The genders of patients were predominantly female. The female to male ratio was 3 to 2 , respectively. The results of the FNAC smear, cell block examination, and tissue biopsy examination are presented in Tables 1-3. The 
most relevant pictures of microscopic examination are placed in (Figures 1-10). Sensitivity and specificity test results of both FNAC smear and Cell block examination are summarized in the following data:

For the FNAC smear examination:

True positive cases $=220 / 225$.

True negative cases $=5 / 225$.

False positive cases $=25 / 225$.

False negative cases $=45 / 225$.
Sensitivity test $=220 / 220+45=220 / 265=83.01 \%$.

Specificity test $=5 / 5+25=5 / 30=16.66 \%$.

For the cell blocks examination:

True positive cases $=220 / 225$.

True negative cases $=5 / 225$.

False positive cases $=0 / 225$.

False negative cases $=5 / 225$.

Sensitivity test $=220 / 220+5=220 / 225=97.77 \%$.

Specificity test $=5 / 5+0=5 / 5=100 \%$.

Table 1: Results of FNAC smear, cell block examination, tissue biopsy in the benign nodules.

\begin{tabular}{|c|c|c|c|c|}
\hline Smear cytology & Cell block examination & Histopathology & No. & $\%$ \\
\hline Inadequate smear in 5 cases & Negative cell block in 5 cases & \multirow{2}{*}{ Lipoma } & \multirow{2}{*}{35} & \multirow{2}{*}{$15.50 \%$} \\
\hline Fat globules in 30 cases & Adipose tissue in 30 cases; $P=0.05$ & & & \\
\hline Fat globule in 10 cases & Fibrofatty tissue in 10 cases & \multirow[b]{2}{*}{ Adipose tissue } & \multirow[b]{2}{*}{30} & \multirow[b]{2}{*}{$13.30 \%$} \\
\hline Fat cells in 20 cases & $\begin{array}{l}\text { Fibrofatty, fibrous bundles in } 20 \text { cases; } \\
\qquad P=0.05\end{array}$ & & & \\
\hline Fat globules, fibroblasts in 20 cases & Fibroadipose tissue in 20 cases; $P=0.05$ & Fibrolipoma & 20 & $8.80 \%$ \\
\hline Fibroblasts in 20cases & $\begin{array}{l}\text { Fibroblasts, fibrous bundles in } 20 \text { cases; } \\
\qquad P=0.001\end{array}$ & Fibroma & 20 & $8.80 \%$ \\
\hline Fibroblasts in 5 cases & $\begin{array}{l}\text { Fibroblasts, fibrous bundles in } 5 \text { cases; } \\
\qquad P=0.001\end{array}$ & Juvenile fibroma & 5 & $2.20 \%$ \\
\hline Fibroblasts, nerve fibrils in 5 cases & $\begin{array}{l}\text { Fibroblasts, nerve fibrils, in } 5 \text { cases; } \\
\qquad P=0.001\end{array}$ & Neurofibroma & 5 & $2.20 \%$ \\
\hline Inadequate smear 10 cases & Fibroadipose tissue in 10 cases & Sebaceous cyst in 25 cases & 25 & $11.10 \%$ \\
\hline Fat cells 15 cases & Fibroadipose tissue in 15 cases; $P=0.05$ & & & \\
\hline Inadequate smear in 5 cases & Benign cells in 5 cases & $\begin{array}{c}\text { Implantation cyst, or dermoid } \\
\text { cyst }\end{array}$ & 20 & $8.80 \%$ \\
\hline $\begin{array}{l}\text { Benign cells, fluid background in } 15 \\
\text { cases }\end{array}$ & Benign in in 15 cases $P=0.05$ & & & \\
\hline $\begin{array}{l}\text { Degenerated cells, others mature } \\
\text { squamous cells in } 5 \text { cases }\end{array}$ & Negative in 5 cases $P=0.0001$ & Pilomatrixioma & 5 & $2.20 \%$ \\
\hline $\begin{array}{l}\text { Epithelial cells with degenerative } \\
\text { changes and pigmentation in } 10 \text { cases }\end{array}$ & $\begin{array}{l}\text { Epithelial cells with degenerative changes } \\
\text { and pigmentation in } 10 \text { cases; } P=0.001\end{array}$ & Seborrheic keratosis & 10 & $4.40 \%$ \\
\hline $\begin{array}{l}\text { Inflammatory cells, sulphur granules in } \\
\qquad 5 \text { cases }\end{array}$ & $\begin{array}{l}\text { Colonies of actinomycosis, inflammatory } \\
\text { cells in } 5 \text { cases' } P=0.001\end{array}$ & Madura foot (actinomycosis) & 5 & $2.20 \%$ \\
\hline
\end{tabular}

Table 2: Results of FNAC smear, cell block examination, tissue biopsy in the benign nodules.

\begin{tabular}{|c|c|c|c|c|}
\hline Smear cytology & Cell block examination & Histopathology & No. & $\%$ \\
\hline Fat cells in 10 cases & Pleomorphic atypical lipoblasts in 10 cases & Atypical Lipoma & 20 & $8.8 \%$ \\
\hline atypical cells (pleomorphic, hyperchromatic) in 10 cases & Atypical lipoblasts in 10 cases; $P=0.05$ & & & \\
\hline
\end{tabular}

Table 3: Results of FNAC smear, cell blocks, and tissue biopsy in malignant nodules.

\begin{tabular}{|c|c|c|c|c|}
\hline Smear cytology & Cell block examination & Histopathology & No. & $\%$ \\
\hline Malignant cells in 10 cases & $\begin{array}{l}\text { Malignant cells, basal cell carcinoma with } \\
\text { peripheral palisading in } 10 \text { cases; } P=0.001\end{array}$ & Basal cell carcinoma & 10 & $4.4 \%$ \\
\hline Tad pole cells, hyperchromatic cells in 10 cases & $\begin{array}{l}\text { Tad pole cells and carcinoma cells in } 10 \text { cases; } \\
\qquad P=0.001\end{array}$ & $\begin{array}{l}\text { Squamous cell } \\
\text { carcinoma }\end{array}$ & 10 & $4.4 \%$ \\
\hline Malignant cells in 5 cases & $\begin{array}{l}\text { Malignant cells, basaloid cells, squamous cells } \\
\text { with cell nest and keratin pearls in } 5 \text { cases; } \\
\qquad P=0.001\end{array}$ & $\begin{array}{l}\text { Basosquamous cell } \\
\text { carcinoma }\end{array}$ & 5 & $2.2 \%$ \\
\hline
\end{tabular}




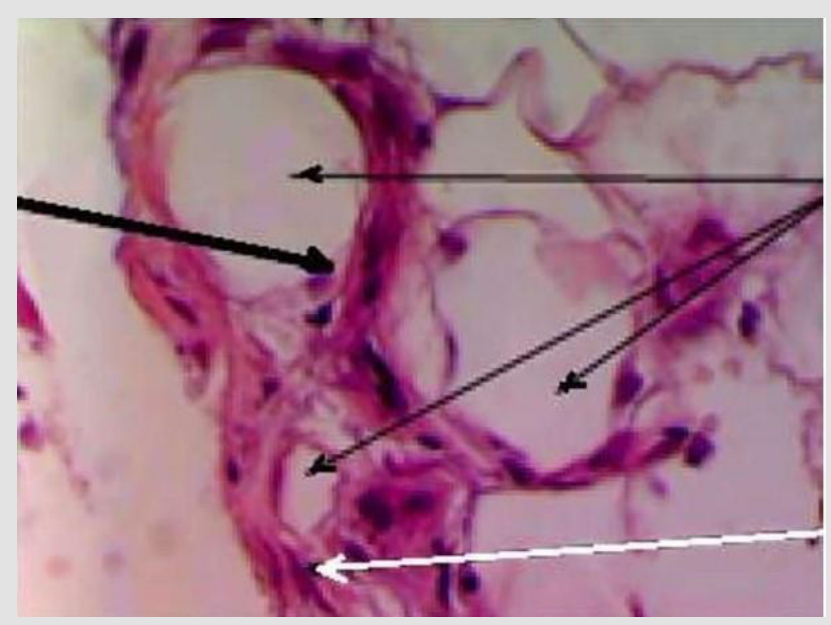

Figure 1: Cell block from a case of fibrolipoma showing mature fat cells (thick arrow), fat globules (thin arrows), fibroblasts and collagen bundles (white arrow). (H\&E, x400).

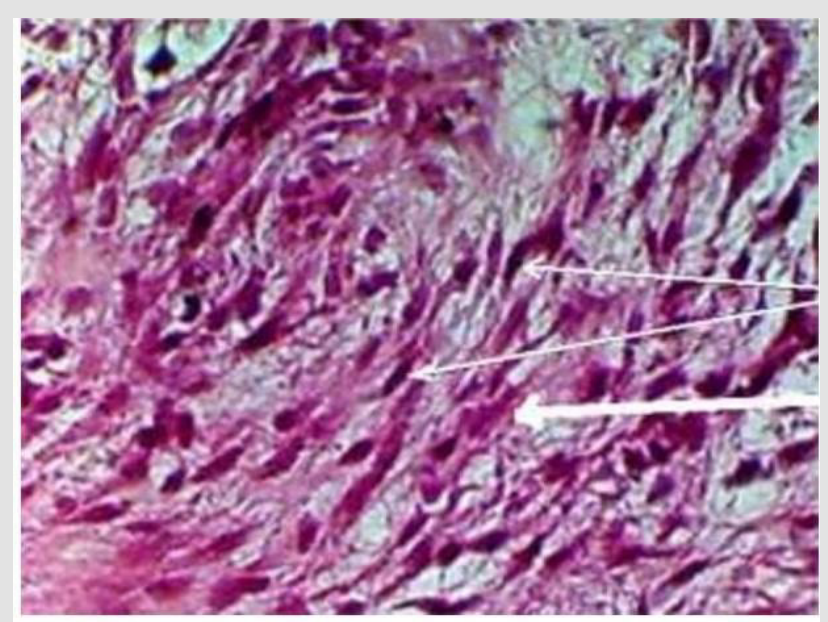

Figure 2: Cell block from a case of juvenile fibroma showing fibroblasts (thin arrows) and thick homogenous collagen bundles (white arrow). (H\&E, x400).

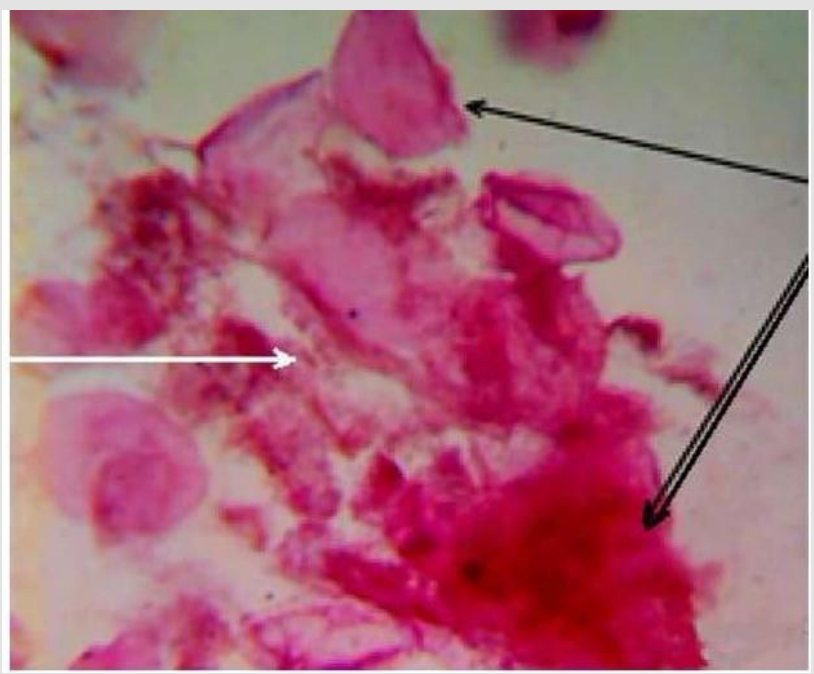

Figure 3: FNAC smear from a case of dermoid cyst showing benign squamous degenerated cells (thin black arrow) and keratinous material (double arrow) in a background of cellular debris (white arrow). (H\&E, x400). 


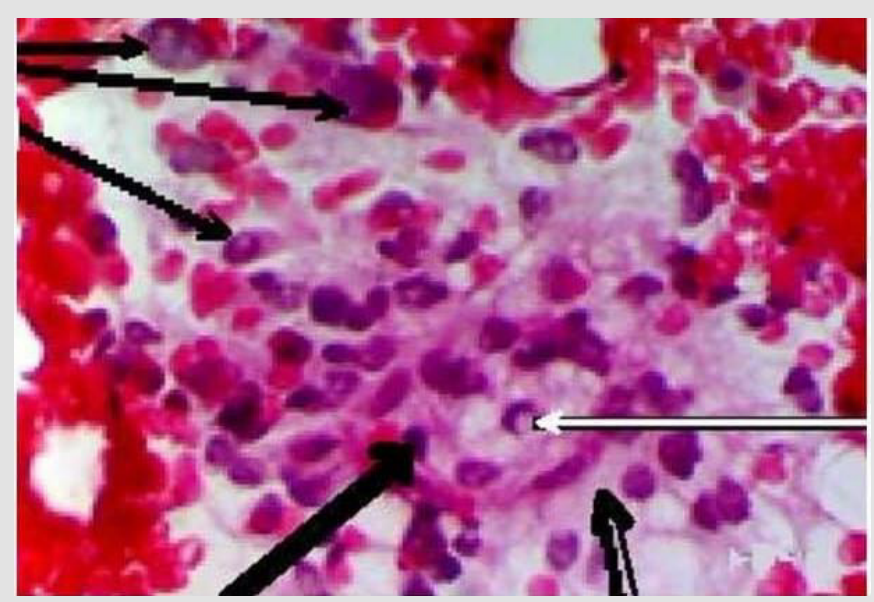

Figure 4: FNAC smear from case of atypical lipoma showing pleomorphic hyperchromtic cells (thin black arrows) and some with pseudo-inclusions in nuclei (thin white arrow). Some apoptotic bodies (thick black arrow) could be seen, but absent mitosis. The background is mucinous with slight vacuoles (double arrow). (H\&E, x400).

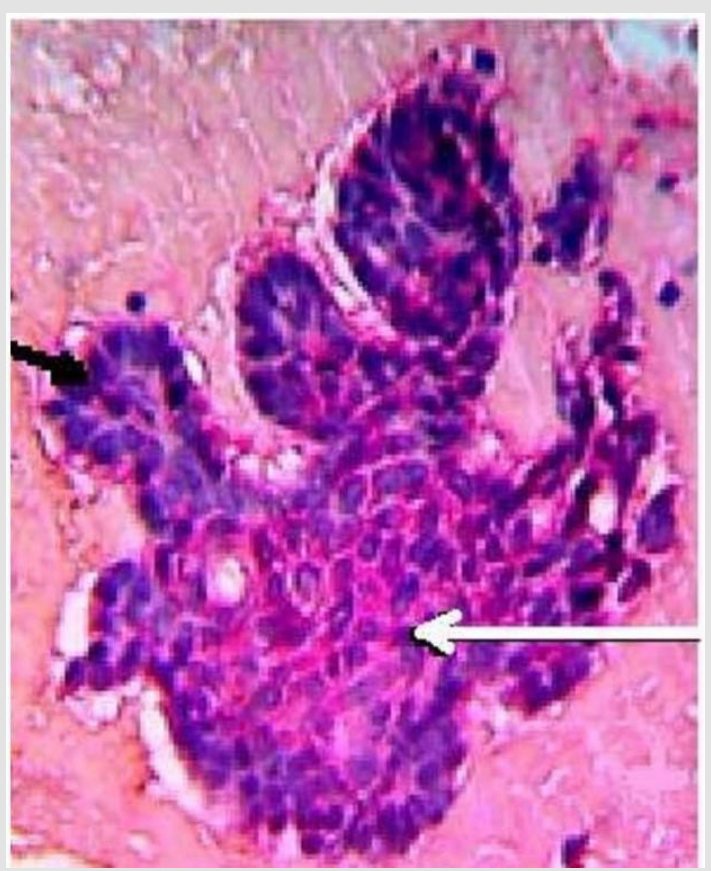

Figure 5: Cell block from a case of basal cell carcinoma, showing malignant basaloid cells (white arrow), peripheral palisading (black arrow). (H\&E, x400).

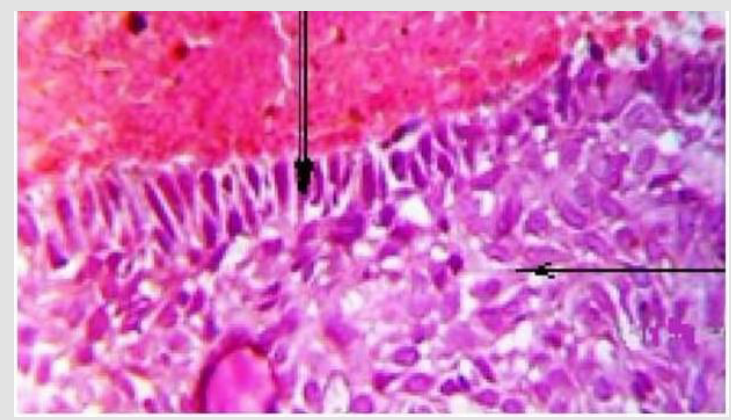

Figure 6: Cell block from a case of basal cell carcinoma showing malignant basaloid cells (double arrow) with peripheral palisading (arrow). (H\& E, x400). 


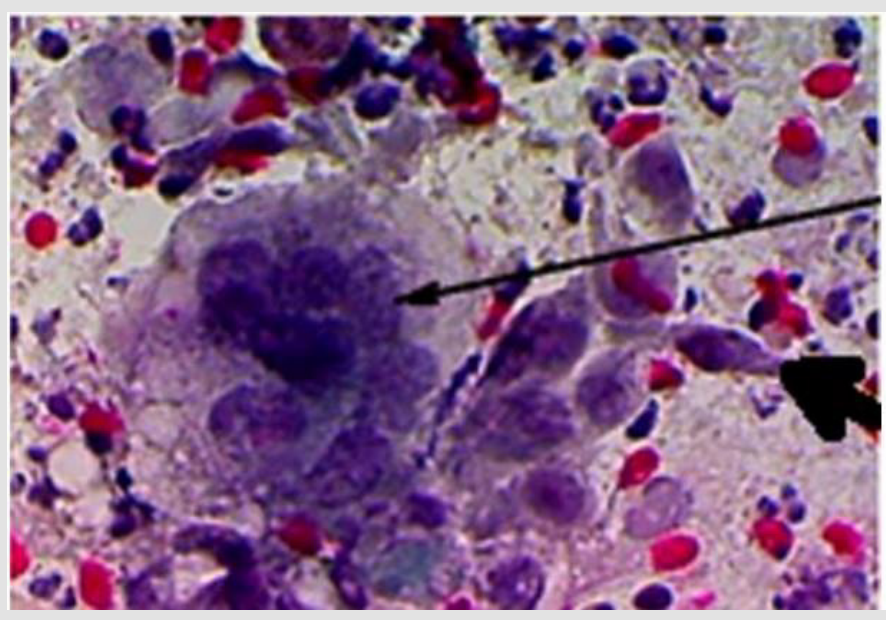

Figure 7: Cell block from a case of squamous cell carcinoma, showing; tap pole malignant squamous cell (thick arrow), overlapped malignant squamous cells (thin arrow). (PAP, x400).

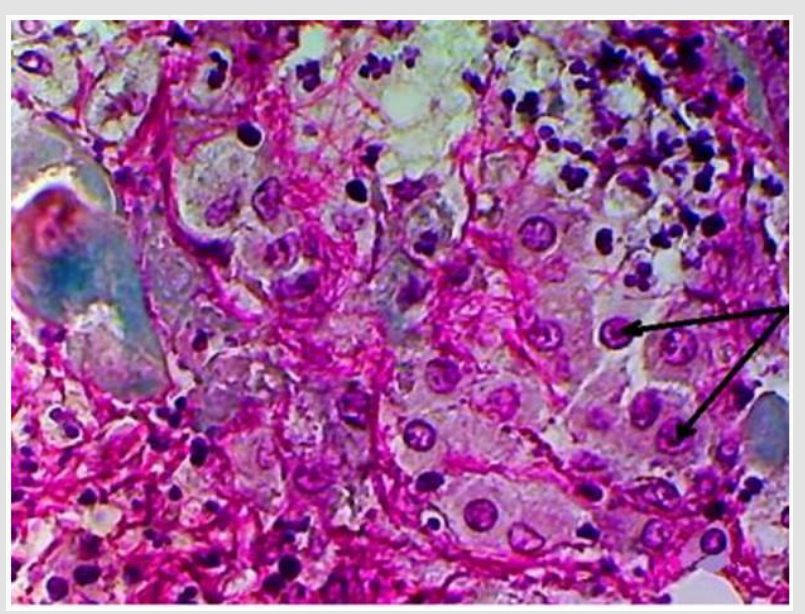

Figure 8: Cell block from a case of squamous cell carcinoma showing malignant squamous cells with prominent nucleoli (arrows). (PAP, x400).

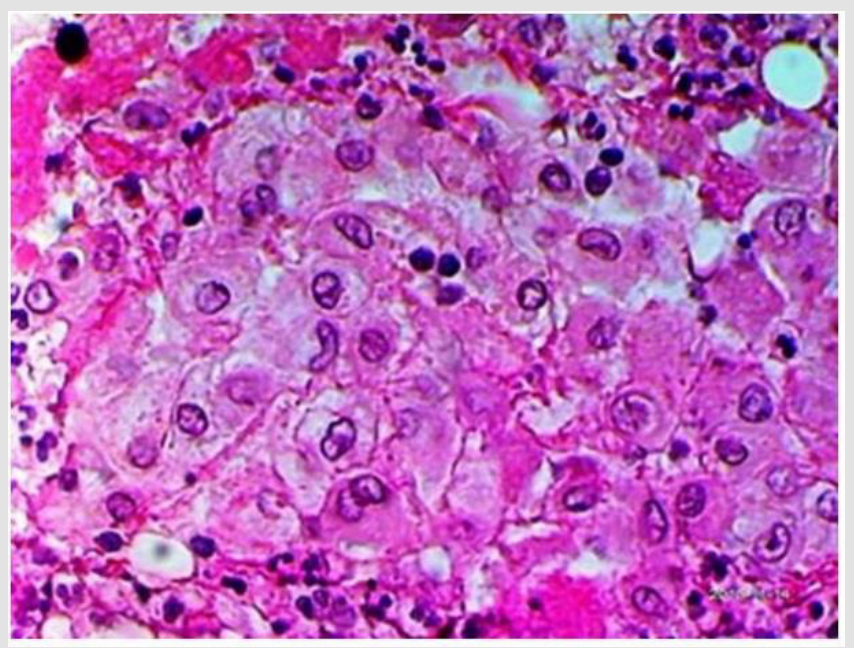

Figure 9: Cell block from a case of Squamous cell carcinoma showing pleomorphic malignant squamous cells. (H\&E, x400). 


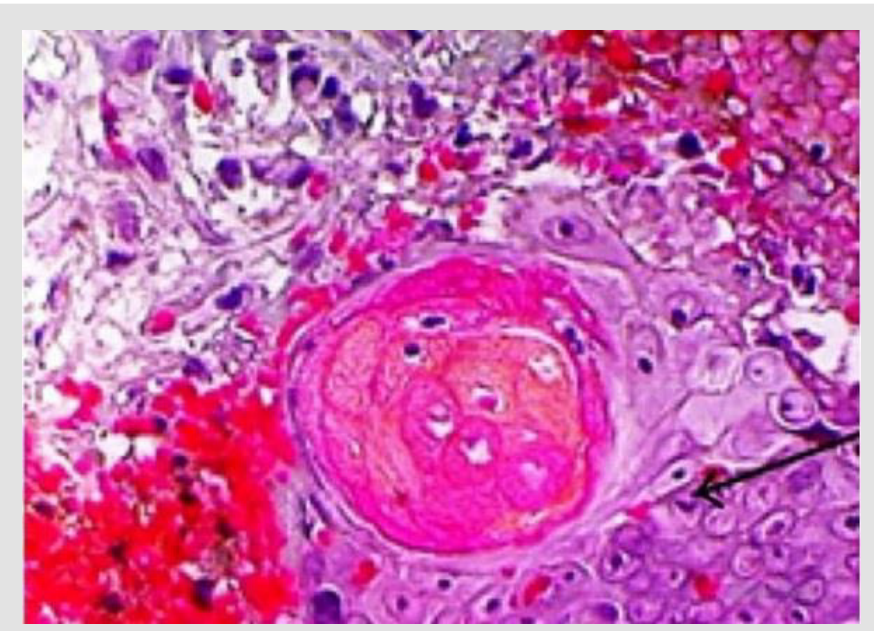

Figure 10: Cell block from a case of squamous cell carcinoma showing malignant squamous cells with prominent nucleoli (thin arrow), keratin pearls. (H\& E, x400).

\section{Discussion}

In this study, we focused on the performance of cell mass and its importance in diagnosing and differentiating lesions due to its simplicity and reproducibility. We performed FNAC smear first, as it is a rapid test to detect the presence and types of cells in general and also to compare the features found in FNAC smear and those in cell blocks. FNAC is an easy to perform and inexpensive technique. It does not disturb the architecture of the lesion and has nothing to do with the promotion of metastasis of malignant lesions, because it is a non-invasive technique and does not harm the patient. It looks similar to intramuscular or subcutaneous injection of any medication using a fine needle. We utilized the clot method for preparation of cell blocks, other methods described by [9] and [10]. We preferred the clotting method because the structural forms of cells and tissues were more preserved. We utilized the same clotting method in preparation of cell blocks in two previous studies and gave excellent results [11]. Patients in this work ranged in age from 2 to 76 years with a greater transition to senescence ( $>40$ years was about $70 \%$ ), and the female to male ratio was 3 to 2 , respectively with no significant outcome. This means that the appearance or complaint of the skin or subcutaneous nodules occurs more often in females and at older ages. For FNAC smear results, the test processed a sensitivity about $83 \%$ that is a significant percentage but lower than that of cell block (97.77\%) This meant that cell block is more sensitive test than FNAC smear. Furthermore, cell block technique is more specific than FNAC smear, (100\%) for cell block, and $16.66 \%$ for FNAC smear).

These results alluded to the role of cell block in appearance of cell orientations which give a picture resembling the tissue biopsy. Similarly, another study reported high sensitivity and specificity of FNAC in diagnosing skin lesions with sensitivity of up to $100 \%$ in epidermal cyst and inflammatory lesions, but showed only $67 \%$ for adnexal tumors [12]. The authors also reported specificity of $50 \%$ for adnexal tumors. In case of benign cyst, the cyst was filled of fluid, so the smear contains scanty cells, which may not appear, and the smear gave an insufficient result. Cell block provided more accurate result, but the performance of cell block may fail because of low cells and need gentle handling. In case of seborrehic keratosis, the smear was insignificant, because the cells were degenerated, with more brown pigmented cells; the features of cells were vague. On contrast in cell block, the benign features of cells were more obvious. This picture gives a confidence in diagnosis as a benign lesion. In cases of lipoma and fibrolipoma, the smear showed fat globules and/or mature fat cells, fibrous elements a picture found by other authors [13]. These features give a confidence of benign lesion, but the specific diagnosis cannot be achieved. The specific diagnosis of lipoma, fibrolipoma can be given easily in cell block. In cases of fibroma; the smear gave a suggestion of benign fibrotic lesion (spindle-shaped fibroblasts and some collagen fibers), but the cell block showed well-formed fibroma. In cases of juvenile fibromas, the smear may be negative because of the dense contents; however, the cell block is specific for diagnosis, moreover, it takes another importance to exclude juvenile fibrosarcoma and fibromatosis (the absence of mitotic activity).

On contrary of the previous lesions, FNAC smear provided satisfactory results that distinguished a benign lesion, and also specific for neurofibroma; because it gave us a picture of twisted nuclei, angulated and a hair-like background of neurofilaments a feature also found by [14]. In cases of pilomatrexioma, the smear gave a picture of benign lesion (ghost cells, mature epithelial cells, giant cells) the same picture found by[15], but the cell block failed in most cases because of the presence of admixed amounts of degenerated, or shadow cells. In cases of dermoid cysts or implantation cysts, the smear showed a mixture degenerated epithelial cells and 
keratinous material, a picture found also by [16], but the cell block also usually failed due to the keratinous material.In cases of atypical lipomas, FNAC smear showed a very useful picture; pleomorphic, hyperchromatic lipoblasts, mucoid background; the cell block did not add a more information. In cases of basal cell carcinoma; FNAC smear showed malignant cells with basophilic cytoplasm; the same results were found by [17], but the orientation of cells appeared in the cell block with peripheral palisading. In cases of squamous cell carcinoma, the malignant epithelial cells and the individual cell keratinization appeared in the smear. The FNAC smear showed a good picture but the specific feature of cell nests and keratin pearls appeared in the cell block. In cases of FNAC smear of basosqaumous cell carcinoma; the smear gave a picture of malignant epithelial cells, but the specific orientation of basosqaumous cell carcinoma appeared in the cell block,In cases of Madura foot, the smear showed mixed inflammatory cell infiltrate which was non-specific, but cell block was very useful to clarify the mycetoma colonies with appearance of peripheral esinophilic clubs; however, [18] could found this feature in the FNAC smear. The flowchart followed in the study and the main results are shown in Figure 11.

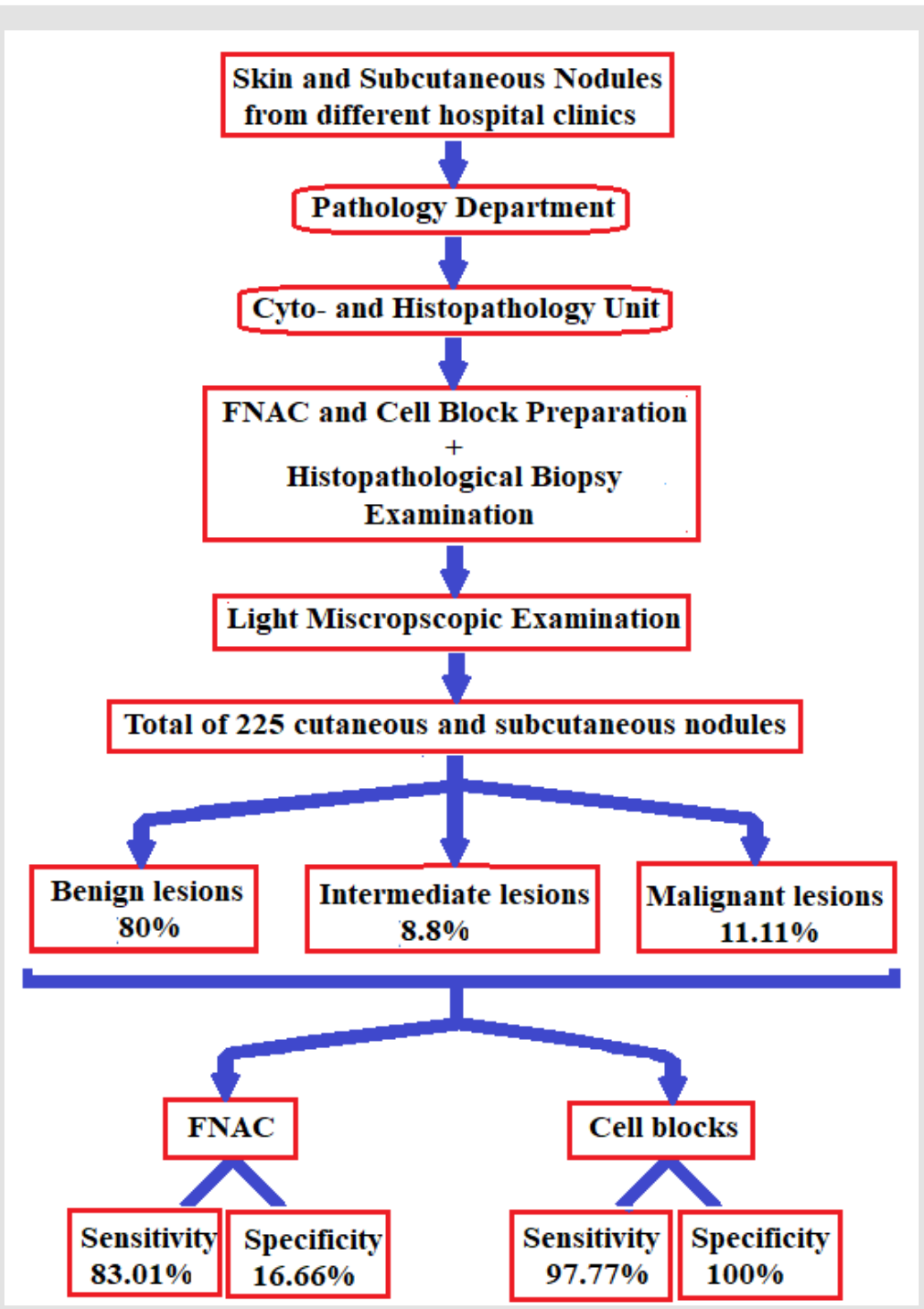

Figure 11: Flowchart showing main steps followed in the study and main findings.

\section{Conclusion}

Cell block study gives a more specific and more orientation of the cells similar to that of tissue biopsy. FNAC smear may give a useful advantage. Some lesions give negative results in smears, others give negative results in cell block. Therefore, we recommend performing FNAC smear as well as cell blocks whenever possible. 


\section{References}

1. Nguyen T, Zuniga R (2013) Skin conditions: benign nodular skin lesions. FP Essent 407: 24-30.

2. Higgins JC, Maher MH, Douglas MS (2015) Diagnosing Common Benign Skin Tumors. Am FAM Physician 92(7): 601-607.

3. Dildar M, Akram S, Irfan M, Khan HU, Ramzan M, et al. (2021) Skin cancer detection: A review using deep learning techniques. Int J Environ Res Public Health 18(10): 5479.

4. Evangelisto A (2006) what is that nodules? A diagnostic approach to evaluating subcutaneous and cutaneous nodules (review article). J Clin Reumatol 12(5): 230-240.

5. Kshatriya AS, Santwani PM (2016) Comparison of FNAC smears, cytospin smears, and cellblocks of transthoracic guided FNAC of suspected lung tumor: A study of 100 cases. J Cytol 33(3): 141-144.

6. Hegazy RA, Hegazy AA, Fetouh FA, Ibrahim S (2014) Fine needle aspiration cytology and cell-block study of various breast lumps. Am J Biomed Life Sci 2(1): 8-17.

7. Hegazy R, Hegazy A (2015) Hegazy' simplified method of tissue processing (consuming less time and chemicals): Ann Int Med Dent Res 1(2): 57-61.

8. Satturwar S, Pantanowitz L (2021) Architectural aspects of cell-blocks as small biopsies. Cytojournal. 18: 5 .

9. Shidham VB (2019) CellBlockistry: Chemistry and art of cell-block making a detailed review of various historical options with recent advances. Cytojournal 16: 12.

\section{ISSN: 2574-1241}

DOI: 10.26717/BJSTR.2021.39.006301

Raafat Awad Hegazy. Biomed J Sci \& Tech Res

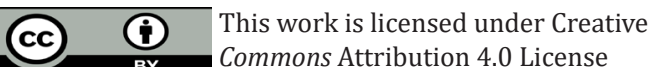

Submission Link: https://biomedres.us/submit-manuscript.php
10. Trevethan R (2017) Sensitivity, Specificity, and Predictive Values: Foundations, Pliabilities, and Pitfalls in Research and Practice. Front Public Health 5: 307.

11. Hegazy RA, Hegazy AA, Fetouh FA, Ibrahim S (2014) Fine needle aspiration cytology and cell-block study of various breast lumps. Am J Biomed Life Sci 2(1): 8-17.

12. Sapna Patel S, Mahadevappa A, Manjunath GV (2016) Fine needle aspiration cytology of papulonodular lesions of skin: A study of 50 cases. Journal of Clinical and Diagnostic Research 10(12): EC09-EC13.

13. Soni PB, Verma AK, Chandoke RK, Nigam JS (2014) A prospective study of soft tissue tumors histocytopathology correlation. Patholog Res Int.

14. Abdellatif E, Kamel D (2021) Soft tissue; Peripheral nerve; Neurofibromageneral, pathology outlines.com.

15. Bansal C, Handa U, Mohan H (2011) Fine needle aspiration cytology of pilomatrixoma, J Cytol 28(1): 1-6.

16. Vaughan VC, Wisell J (2020) Skin nonmelanocytic tumor- Cysts, Epidermal (epidermoid) type.

17. Pasquali P, Segurado-Miravalles G, Castillo M, Fortuño Á, Puig S, González $S$ (2020) Use of Cytology in the Diagnosis of Basal Cell Carcinoma Subtypes. J Clin Med 9(3): 612.

18. Afroz N, Khan N, Siddiqui FA, Rizvi M (2010) Eumycetoma versus actinomycetoma: Diagnosis on cytology. J Cytol Oct 27(4): 133-135.

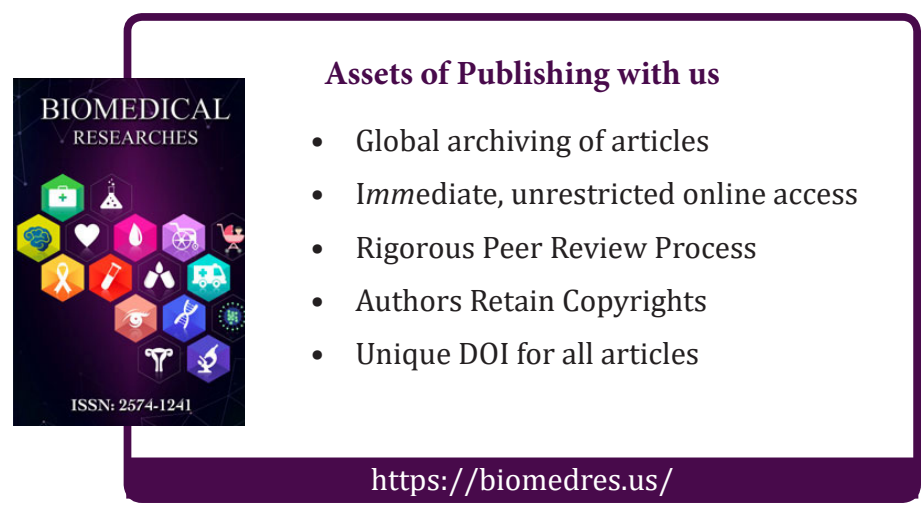

